\title{
The nature of consciousness in the visually deprived brain
}

\author{
Ron Kupers ${ }^{1}$, Pietro Pietrini ${ }^{2}$, Emiliano Ricciardi ${ }^{2}$ and Maurice Ptito ${ }^{3,4}$ \\ 1 Institute of Neuroscience and Pharmacology, Panum Institute, University of Copenhagen, Copenhagen, Denmark \\ 2 Laboratory of Clinical Biochemistry and Molecular Biology, University of Pisa, Pisa, Italy \\ ${ }^{3}$ Chaire Harland Sanders en Sciences de la Vision, École d'Optométrie, Université de Montréal, Montréal, OC, Canada \\ ${ }^{4}$ Danish Research Center for Magnetic Resonance, Hvidovre Hospital, Hvidovre, Denmark
}

\section{Edited by:}

Morten Overgaard,

Aarhus University, Denmark

Reviewed by:

Ryota Kanai,

University College London, UK

Steven Laureys,

University of Liège, Belgium

${ }^{*}$ Correspondence:

Ron Kupers, Institute of Neuroscience and Pharmacology, Panum Institute,

Copenhagen University, Blegdamsvej 3B, DK-2200 Copenhagen, Denmark. e-mail: ron@pet.rh.dk
Vision plays a central role in how we represent and interact with the world around us. The primacy of vision is structurally imbedded in cortical organization as about one-third of the cortical surface in primates is involved in visual processes. Consequently, the loss of vision, either at birth or later in life, affects brain organization and the way the world is perceived and acted upon. In this paper, we address a number of issues on the nature of consciousness in people deprived of vision. Do brains from sighted and blind individuals differ, and how? How does the brain of someone who has never had any visual perception form an image of the external world? What is the subjective correlate of activity in the visual cortex of a subject who has never seen in life? More in general, what can we learn about the functional development of the human brain in physiological conditions by studying blindness? We discuss findings from animal research as well from recent psychophysical and functional brain imaging studies in sighted and blind individuals that shed some new light on the answers to these questions.

Keywords: vision, blindness, consciousness, qualia, cross-modal plasticity, supramodality, rewiring
If we could splice the nerves so that the excitation of the ear fed the brain centre concerned with seeing, and vice versa, we would "hear the lightning and see the thunder"

William James, Principles of Psychology, Dover, New York, 1890

\section{INTRODUCTION}

The study of brain function in individuals with congenital blindness provides a unique approach to understand how consciousness develops in the absence of sight. Classically, sight has always been regarded as the most important sense for humans to interact with the environment. In the ancient Greek language the verb "to know" (oilda) was the past tense of the verb "to see" (oJravw), that is, "I saw and thus I know." The relevance of sight is also clearly reflected in the mental attitude senses of the lexicon of vision. Consider everyday linguistic uses such as "I see what you mean," "Do you see my point?" etc. At the same time, the amount of brain surface devoted to visual function in primates is remarkably high, accounting for almost one-third of the whole cortex. This predominance of vision in primates raises some critical questions. How do individuals who never had any visual experience since birth form a conscious representation of a world that they have never seen? How do their brains behave? What happens to visiondevoted brain structures in individuals who are born deprived of sight or who lose vision at different ages? To what extent is visual experience truly necessary for the brain to develop its functional architecture? What does the study of blind individuals teach us about the functional organization of the sighted brain in physiological conditions? We attempt to shed some new light on these old questions by reviewing evidence from studies conducted in animals and in humans.

\section{ANIMAL STUDIES}

Early experience plays a key role in the development of the nervous system as the brain has to adapt continuously to environmental changes that threaten its harmonious development. This adaptation phenomenon is called brain plasticity and refers to the lifelong changes in the structure of the brain that accompany experience (experience-dependent plasticity). This concept suggests that the brain is pliable, like plastic, and can be molded into different forms in response to changes in the environment such as sensory deprivation, brain injuries or abnormal development. Indeed, several regimens of visual deprivation such as dark-rearing, enucleation, or eye-lid suturing lead to alterations of the visual system. Conversely, environmental enrichment also produces regional changes in brain anatomy such as increased dendritic space for synapses, increased cortical thickness, and elevated gene expression (Ptito and Desgent, 2006).

\section{CROSS-MODAL PLASTICITY}

The loss of a particular sense leads to the invasion of the deprived cortical area by inputs originating from other modalities, illustrating the remarkable capacity of the cerebral cortex for plasticity and reorganization (Ptito and Desgent, 2006; Pietrini et al., 2009; Merabet and Pascual-Leone, 2010). These inter-modal connections result from a phenomenon called cross-modal plasticity. As early as 1977, Rebillard et al. (1977) reported that the primary auditory cortex in congenitally deaf cats is driven by visual stimuli. Conversely, studies on the microphthalmic mole rat (Spalax ehrenbergi) have shown that auditory stimulation can drive neurons in the primary visual cortex (Bronchti et al., 2002). Cells in the primary visual cortex of visually deprived mice, rats, cats, or monkeys respond to somatosensory or auditory inputs, suggesting cross-modal 
reorganization (Toldi et al., 1994). For example, neurons in visual cortical areas 19 in monkeys with early visual deprivation respond to somatic inputs such as manipulating the experimenter's hand in search for food (Hyvarinen et al., 1991). Peripheral inputs play a pivotal role in the organization of the neocortex, as cortical territories usually involved in visual processing are invaded by the auditory and somatosensory system. It seems therefore that the visual cortex is capable of rewiring in order to accommodate these non-visual inputs. In the case of early brain damage, however, abnormal neuronal connectivity patterns can be produced and an alternative approach to study cross-modal plasticity resides in the tampering with "blue prints" during prenatal development. Relevant to this approach are the numerous studies on "rewiring" in hamsters (Ptito and Desgent, 2006) and in ferrets (reviewed in Lyckman and Sur, 2002).

\section{"REWIRING" THE BRAIN OF HAMSTERS}

If brain damage occurs during development, abnormal neuronal connectivity patterns can develop. It is thus possible to induce, by lesioning central retinal targets, the formation of new and permanent retinofugal projections into non-visual sites such as the thalamic auditory nucleus (Frost and Metin, 1985; Ptito et al., 2001a; Figure 1A). These surgically induced retinal projections are retinotopically organized and make functional synapses (Metin and Frost, 1989). Neurons in the somatosensory cortex of animals with ectopic retinal projections have visual response properties similar to those of neurons in the primary visual cortex of normal sighted animals (Metin and Frost, 1989). Ferrets without visual cortex but with retinofugal projections to the auditory thalamus appear to perceive light stimuli as visual (von Melchner et al., 2000). The question concerning the parallelism between a different brain organization (produced by lesions) and a behavioral recovery is still debated although recent experiments in rewired ferrets and hamsters suggest a large degree of recovery in visual functions (reviewed in Ptito et al., 2001a). For example, responses to visual stimuli have been observed in the auditory cortex of hamsters with robust and permanent projections to the auditory thalamic nucleus (medial geniculate body) but lacking a visual cortex. Single neurons in the auditory cortex of these animals respond to visual stimuli and some respond equally well to visual as to auditory stimuli. Moreover,
A

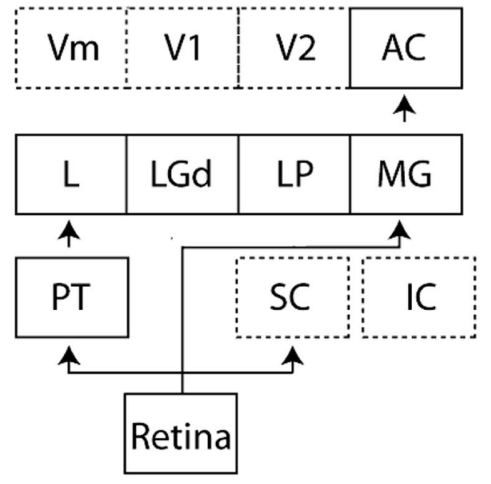

B

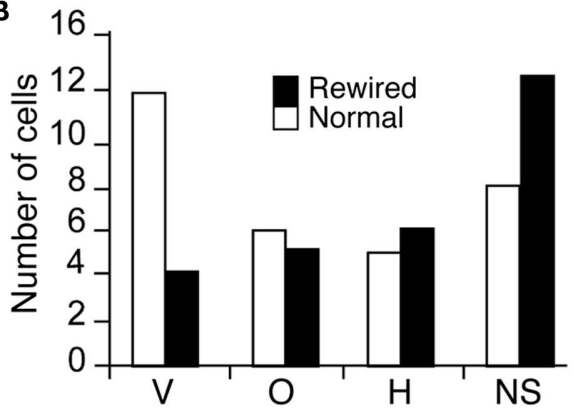

C Normal animals

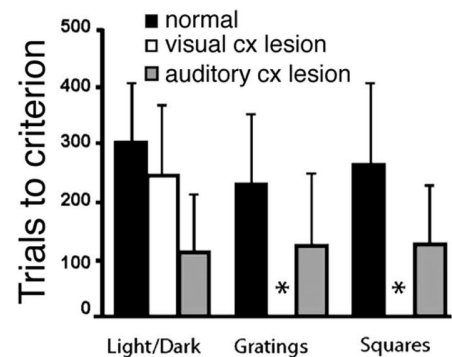

D

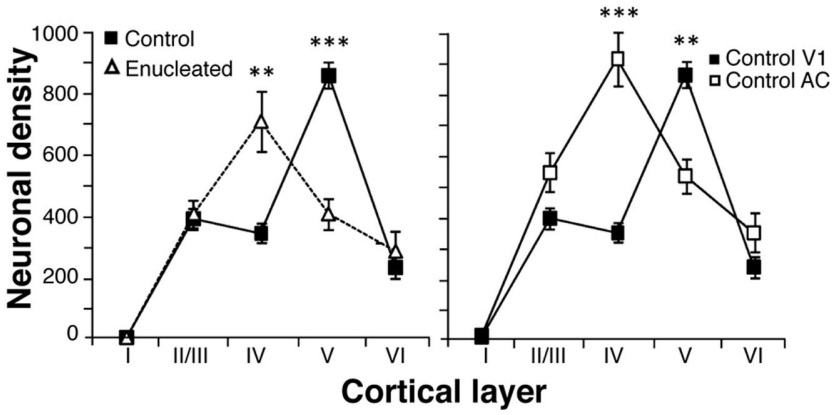

FIGURE 1 | Behavioral and physiological effects of surgically created ectopic retinal projections to the auditory cortex in hamsters. (A) Neonatal lesions of primary retinal targets $(\mathrm{SC})$ and subsequent destruction of cortical visual areas $(\mathrm{V} 1, \mathrm{~V} 2$, and $\mathrm{Vm})$ produce a strong projection from the retina to the auditory cortex (AC). (B) Comparison of the distribution of preferred orientations for cells in area $\mathrm{V} 1$ (normal animals) and area A1 (rewired animals). The auditory cortex in rewired hamsters adopts receptive field properties of the primary visual cortex such as orientation selectivity. Neurons within $\mathrm{A} 1$ of rewired hamsters respond to horizontal $(\mathrm{H})$, vertical $(\mathrm{V})$, and oblique $(\mathrm{O})$ stimulus orientations. All orientations are represented but with no preference bias for vertical orientations as seen in normal animals and with an increased number of non-specific cells (NS).
(C) Rewired hamsters learn visual discrimination tasks as well as normal animals. In normal animals, a bilateral V1 lesion abolishes pattern discrimination. The same result is obtained with a lesion of the auditory cortex in rewired animals (shown by the asterisks). (D) Neuronal density of parvalbumin-immunoreactive cells (PV-Ir) within layers of the auditory and visual cortices in normal and enucleated hamsters. In V1 of control animals, PV-Ir are mainly found in layer V and in lesser density in layer IV. Following enucleation, the density of PV-Ir neurons is now greater in layer IV than the controls. This contrasts with the lower density of PV-Ir neurons in layer $\mathrm{V}$. The resulting pattern of laminar distribution of PV-Ir cells in the primary visual cortex resembles that of the primary auditory cortex (adapted from Ptito et al., 2001a; Ptito and Desgent, 2006; Desgent et al., 2010). 
cells responding to visual stimuli show orientation selectivity and motion and direction sensitivity (Figure 1B). These receptive field properties compare favorably well with those obtained from cells in the visual cortex of normal hamsters (Ptito et al., 2001a).

At the behavioral level, rewired hamsters can learn visual discrimination tasks as well as normal animals and a lesion of the auditory cortex abolishes this function (Figure 1C; Frost et al., 2000). In fact, rewired hamsters with auditory cortex lesions exhibit cortical blindness similar to non-rewired hamsters with visual cortex lesions.

\section{POSSIBLE ROLE OF GABA AND CALCIUM BINDING PROTEINS}

The mechanisms responsible for this cross-modal processing of sensory information in the cortex are not yet fully understood. Recent work carried out in our laboratory has lead to suggest that the observed changes may be due to modifications in GABAergic interneurons expressing the calcium binding proteins parvalbumin and calbindin (Desgent et al., 2010). In deaf and cross-modal rewired ferrets, qualitative changes occur in the morphology and proportion of parvalbumin and calbindin containing interneurons (Pallas, 2001, 2002). Since the laminar distribution of these proteins is significantly different in the primary visual and auditory cortices of normal hamsters (Desgent et al., 2005), specific sensory processing would require adapted cortical microcircuits and would therefore support the hypothesis of a non-stereotypical organization of cortical interneurons. The induction of aberrant connectivity to these cortices is also evident at the neurochemical level. Indeed, hamsters enucleated at birth show not only a reduction in visual cortex volume but also changes in the distribution of calcium binding proteins within that visual cortex (Desgent et al., 2010). Compared to intact hamsters, the density of parvalbuminimmunoreactive neurons in V1 of enucleated animals is higher in layer IV and lower in layer V, whereas the density of calbindinimmunoreactive cells is significantly lower in layer V (Figure 1D). These results suggest that the affected primary visual cortex may adopt chemical features of the auditory cortex through cross-modal rewiring and therefore support the non-stereotypical organization of cortical interneurons.

\section{HOW ABSENCE OF VISION RESHAPES THE HUMAN BRAIN}

How does absence of vision since birth affect the macrostructural organization of the human brain and through which pathways can non-visual information be funneled to the occipital cortex in the visually deprived brain? In recent years, magnetic resonance imaging (MRI)-based brain imaging techniques such as voxelbased-morphometry (VBM), diffusion tensor imaging (DTI), and diffusion tensor tractography (DTT) have been successfully applied for the in vivo investigation of alterations in gray and white matter in the blind human brain. The results of these studies concur that there are changes in both gray and white matter. In addition, metabolic changes have also been documented.

\section{CHANGES IN GRAY MATTER}

The results of VBM studies have revealed a significant gray matter atrophy of all brain structures of the visual pathways, including the lateral geniculate nucleus (LGN), the posterior pulvinar, the striate and extrastriate visual areas and the inferior temporal gyrus and lat- eral orbital cortex, regions that are part of the ventral stream which is involved in object recognition (Noppeney et al., 2005; Shimony et al., 2006; Pan et al., 2007; Ptito et al., 2008b; Figure 2A). These changes are massive with volume reductions ranging from $20 \%$ in extrastriate visual areas up to $25 \%$ in the primary visual cortex (Ptito et al., 2008b). Gray matter reductions also occur in nonvisual areas such as the hippocampus (Chebat et al., 2007; Fortin et al., 2008), the extrapyramidal motor system (caudate, lenticular nuclei, and fornix), the prefrontal cortex and the posterior insula. Besides these volumetric reductions in gray matter, congenitally blind subjects show an increase in cortical thickness in the cuneus (Figure 2B) which is likely due to a reduction in pruning during the early maturation phase of the cortex, resulting from the absence of visual input.

\section{CHANGES IN WHITE MATTER}

White matter changes include atrophy of the optic tracts and the optic chiasm, the optic radiations, the splenium of the corpus callosum (Noppeney et al., 2005; Shimony et al., 2006; Pan et al., 2007; Ptito et al., 2008b) and the inferior longitudinal fasciculus (Ptito et al., 2008b), a pathway connecting the occipital cortex with the temporal lobe. Lesions of this pathway may induce visual agnosia, prosopagnosia, and disturbances in visual recent memory (Tusa and Ungerleider, 1985). No studies found direct evidence for the establishment of new fiber pathways, although volume increases in the occipito-frontal fasciculus, the superior longitudinal fasciculus and the genu of the corpus callosum have been reported (Ptito et al., 2008b). There is also indirect evidence for an increased functional connectivity between somatosensory and visual areas in the congenitally blind brain (Wittenberg et al., 2004; Ptito et al., 2005; Kupers et al., 2006). A recent study using dynamic causal modeling of functional MRI (fMRI) data acquired during an auditory discrimination task points in the direction of increased effective connectivity between the primary auditory and visual cortices in congenitally blind subjects (Klinge et al., 2010). Results with respect to increased thalamocortical connectivity were inconsistent, arguing against strengthening of thalamocortical connections in congenital blindness. It remains a matter of debate whether the increased connectivity between the primary visual cortex and the primary auditory and somatosensory cortical regions involves a direct monosynaptic or an indirect polysynaptic pathway via multisensory association areas (Fujii et al., 2009; Klinge et al., 2010). Taken together, since no de novo tracts have been demonstrated in congenitally blind subjects, the data suggest that cross-modal functionality of the visual cortex in early blindness is primarily mediated by preserved or strengthened cortico-cortical connections.

\section{METABOLIC CHANGES}

Besides structural changes, the occipital cortex of congenitally blind individuals also undergoes important metabolic changes. We measured brain glucose metabolism by using positron emission tomography (PET) in combination with 18-fluoro-D-deoxyglucose (18-FDG) in a group of 12 congenitally blind and 13 sighted individuals. We found that glucose metabolism at rest is increased by around $15 \%$ in both the striate and the extrastriate cortex of congenitally blind compared to sighted individuals. Figure $2 \mathrm{C}$ shows resting-state glucose metabolism in representative examples of a congenitally 


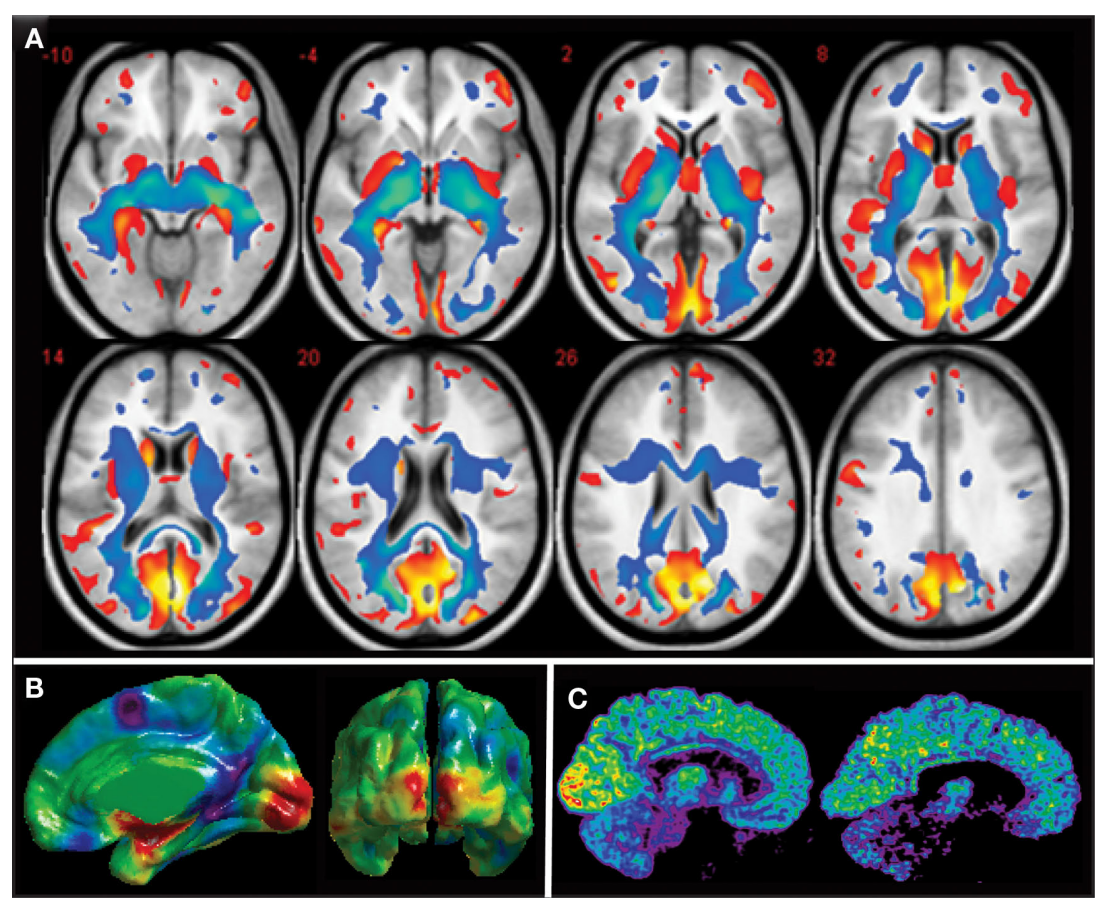

FIGURE 2 |Anatomical and metabolic changes in the congenitally blind brain. (A) Axial brain slices showing reductions in gray (red) and white matter (blue) in congenitally blind compared to matched sighted control subjects. All components of the visual system in the blind are reduced in volume (after Ptito et al., 2008b). (B) Differences in cortical thickness between congenitally blind and sighted control subjects. Despite a reduction in volume of the occipital cortex, cortical thickness of the cuneus is increased in congenitally blind subjects (unpublished data from our lab). (C) Mid-sagittal brain slices showing increased resting-state glucose metabolism in the congenitally blind brain. Illustrative examples of cerebral glucose metabolism in a congenitally blind (left) and a normal sighted control (right) subject (Kupers et al., 2009). blind and a blindfolded control subject. Several mechanisms can be put forward to explain this increased glucose metabolism. One of the hypotheses that we favor is that it reflects internally guided cognitive activity during the FDG-uptake period while subjects are in the "resting" state. Functional brain imaging protocols and studies using transcranial magnetic stimulation (TMS) indeed have shown that the occipital cortex in the congenitally blind is recruited by and effectively involved in a variety of cognitive functions such as lexical, semantic and phonological processing, attention, verbal memory, working memory, etc. (Amedi et al., 2003; Pietrini et al., 2004; Kupers et al., 2007, 2010; Raz et al., 2007; Stevens et al., 2007; Bonino et al., 2008; Cattaneo et al., 2008; Renier et al., 2010).

\section{HOW DO WE ACQUIRE KNOWLEDGE OF THE EXTERNAL WORLD? \\ THE FUSIFORM FACE AREA AND THE PARAHIPPOCAMPAL PLACE AREA...: IS THERE A BRAIN AREA FOR EVERYTHING?}

How we make sense of the infinite number of distinct objects that unfold in front of our eyes has been a matter of fascinating debates for philosophers and scientists since the early days. In the past two decades, based on the results from single-cell recordings in nonhuman primates and functional brain imaging studies in humans, some authors have proposed the existence of a "fusiform face area" and a "parahippocampal place area," specifically devoted to recognition of faces and places, respectively (Kanwisher et al., 1997; McCarthy et al., 1997).
An alternative interpretation proposes that different areas in the extrastriate ventrotemporal cortex are specialized in different types of perceptual processes. According to this theory, the fusiform face area would be responsible for expert recognition of items from any category, not merely faces (Gauthier et al., 1999, 2000). Thus, the fusiform face area would respond to a face not just because it is a face but because of the fact that all of us are "face-experts" as we begin to look at faces since the very first days of life.

While for face and place recognition, and perhaps a few additional categories, it appears plausible that evolution might have led to the selection of dedicated neural systems given their biological meaning for survival, this certainly cannot be true for the vast majority of object categories. In the first place, the total amount of cortical surface in the ventral object vision pathway is rather limited; second, an evolution-based selection of specific neuronal groups that respond in an all-or-none manner to each distinct category would be simply impossible in terms of time required for evolutionary selection mechanisms to operate. A further strong objection comes from recent studies using fMRI that have demonstrated that looking at a face not only elicits a peak response in the lateral fusiform gyrus, but also additional activations outside of the fusiform gyrus (Ishai et al., 1999). On the other hand, other non-face object categories do activate the lateral fusiform gyrus, although to a lesser degree than faces (Ishai et al., 1999). 


\section{OBJECT FORM TOPOLOGY}

To resolve this issue, Haxby et al. (2001) used fMRI to measure brain responses to different object categories, including human faces, cats, houses, and man-made objects. They demonstrated that different object categories elicit specific neural response patterns that are not restricted to selected subregions within the extrastriate ventrotemporal cortex but are rather widely distributed and overlapping. In other words, the extrastriate ventrotemporal cortex is able to produce an infinite number of neural response patterns specific for each category of objects being viewed (Haxby et al., 2001). Indeed, response patterns were so specific that it was possible to predict what the subject was actually looking at. Moreover, the specificity of the patterns changed only minimally even when the voxels with the maximal response to a given category had been removed from the analysis, indicating that the specificity of the neural response is truly distributed within the extrastriate ventrotemporal cortex and is not due to activity in a restricted area that drives the correlation. The functional architecture proposed by this model, named "object form topology," embodies the capacity of the inferior surface of the temporal lobe to generate unique representations for a virtually unlimited number of object categories.

\section{DOES VISUAL CORTEX REQUIRE VISION TO DEVELOP AND FUNCTION?}

The demonstration that the representation of a face or object is sustained by a widely distributed neural activity within the ventral temporal cortex raises further questions. Is object form topology in these cortical areas strictly visual or does it represent a more abstract, supramodal, functional organization? Next, is visual experience a mandatory prerequisite for this functional organization to develop?

To address these questions, we used fMRI to measure brain responses in a group of blindfolded sighted subjects while they performed non-visual object recognition tasks. Tactile recognition of face-masks and man-made objects of daily use elicited distinct category-specific patterns of neural response in the extrastriate ventral temporal cortex, that were similar to those elicited by visual recognition (Haxby et al., 2001) of the same object categories (Figure 3A; Pietrini et al., 2004). Furthermore, the neural response patterns elicited by tactile perception of bottles or shoes, the two man-made object categories in the study, correlated significantly with those evoked by visual perception of the same object category, indicating that these neural response patterns are supramodal in nature; that is, that they are not merely restricted to visual perception (Pietrini et al.,

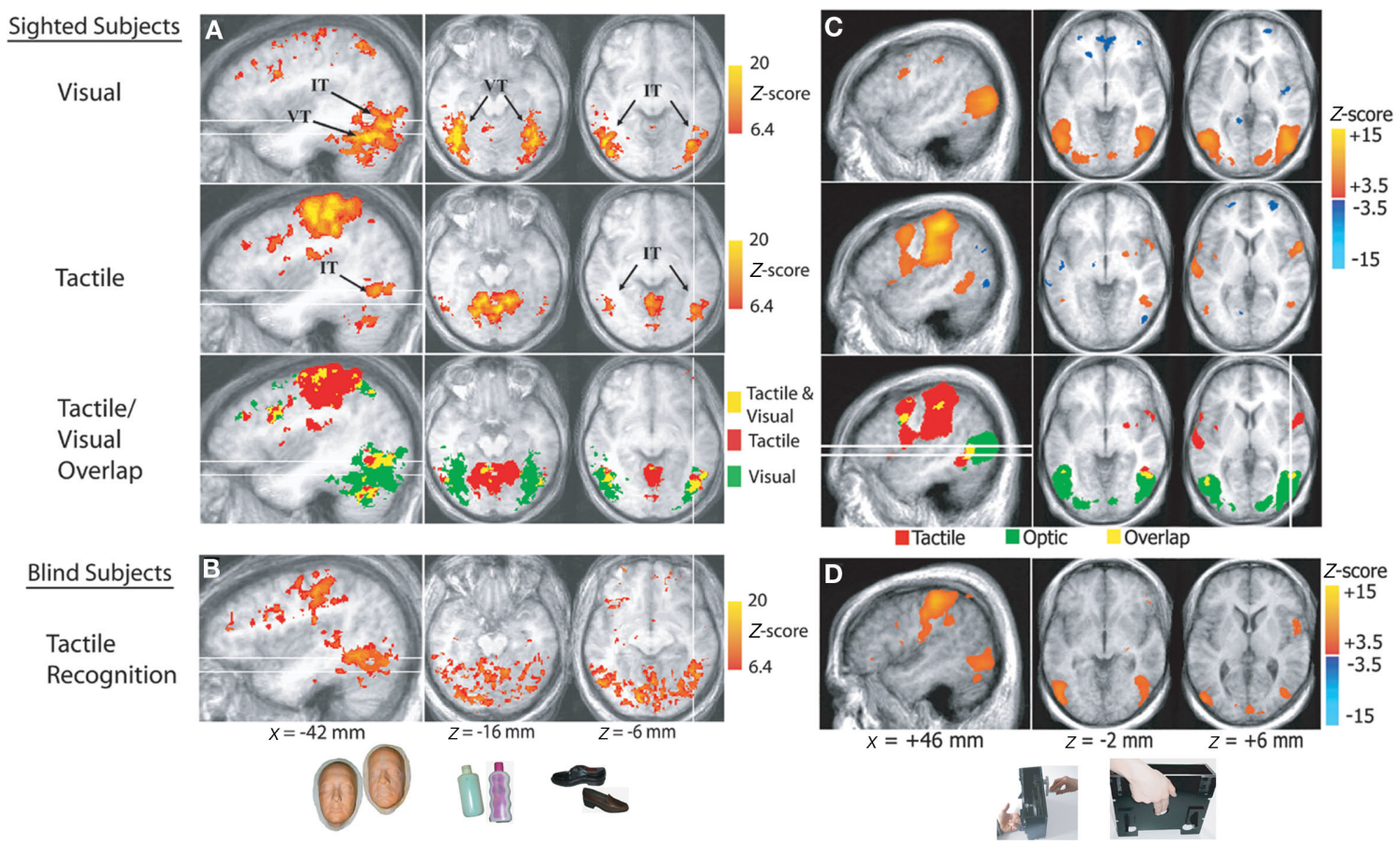

FIGURE 3 | Supramodal neural response patterns in the human brain. (A,B) Supramodal neural response in extrastriate ventral temporal cortex. Below, examples of stimuli (life masks of faces, plastic bottles, and shoes) used during tactile and visual recognition of different object categories in sighted and congenitally blind subjects. Brain areas that responded during tactile and/or visua object perception in sighted subjects and during tactile perception in blind individuals. The inferior temporal (IT) and ventral temporal (VT) regions activated by tactile and visual object perception are indicated. The tactile/visual overlap map shows the areas activated by both tactile and visual perception (shown in yellow), as well as the areas activated only by tactile (red) and visual (green) perception.
The white lines correspond to the locations of the sagittal and axial slices. (C,D) Supramodal neural response in hMT+ cortex. Braille-like dot patterns moved on a plastic surface to provide translational and rotational tactile flow stimulation. Subjects' hands lay on the table with the index and middle fingers touching the plastic surface with dot patterns, as shown at the bottom of the picture. Brain areas are shown that responded during tactile or optic flow perception in sighted subjects and during tactile flow perception in blind subjects. The tactile/visual overlap map shows the areas activated by both tactile and optic flow perception (shown in yellow), as well as the areas activated only by tactile (red) and optic (green) perception (modified from Pietrini et al., 2004; Ricciardi et al., 2007). 
2004, 2009). Of note, congenitally blind individuals showed categoryspecific neural response patterns in the ventral temporal extrastriate cortex during the same tactile object recognition task that were similar to those measured in sighted controls (Figure 3B).

Our findings expand results from other laboratories that in sighted individuals visual and tactile object perception activate the dorsal part of the lateral occipital cortex (LOC proper; Amedi et al., 2001,2002; James et al., 2002) by showing a cross-modal correlation of response patterns between the two sensory modalities. In addition, our results in congenitally blind individuals clearly indicate that visual imagery cannot account for the visual cortex activation during the tactile task (James et al., 2002; Sathian and Zangaladze, 2002; Matteau et al., 2008). Indeed, while it has been shown that seeing an object or recalling the image of that object through visual imagery leads to similar neural responses in the brain (Ishai et al., 2000; O'Craven and Kanwisher, 2000; Ishai, 2010), visually based imagery is by definition absent in congenitally blind or early blind subjects with no recollection of visual experience (though congenitally blind subjects do have imagery! See review by Cattaneo et al., 2008).

The findings in the congenitally blind subjects are important also because they indicate that the development of topographically organized, category-related representations in the extrastriate visual cortex does not require visual experience. Experience with objects acquired through other sensory modalities appears to be sufficient to support the development of these patterns. Thus, at least to some extent, the visual cortex does not require vision to develop its functional architecture that makes it possible to acquire knowledge of the external world.

\section{SUPRAMODAL FUNCTIONAL ORGANIZATION OF THE DORSAL STREAM}

In light of the evidence discussed above indicating a supramodal functional organization independent from visual experience in the ventral "what" pathway, we asked whether the dorsal "where" pathway, that is devoted to spatial processing (Ungerleider and Mishkin, 1982; Haxby et al., 1994) also shows a similar property. To test this hypothesis, we compared fMRI responses while sighted subjects and individuals with congenital or early blindness and no recollection of visual experience performed distinct spatial perception tasks through the visual and/or tactile modalities. In a study using a one-back spatial discrimination task, sighted and congenitally/ early blind subjects had to indicate whether a visually and/or tactilely presented matrix was the same or different as compared with the previous one. In the tactile spatial discrimination task, both groups activated a fronto-parietal network that extended bilaterally from dorsolateral prefrontal and anterior cingulate cortex toward fronto-parietal sensorimotor and posterior parietal cortical regions, including precuneus and intraparietal sulci (Ricciardi et al., 2006a; Bonino et al., 2008). A similar fronto-parietal network was activated during the visual version of the spatial task in the sighted subjects, indicating that the dorsal cortical pathway is capable of processing both visual and non-visual spatial information.

\section{PROCESSING OF MOTION BY VISION OR TOUCH}

Concurrent processing of spatial information and motion discrimination is crucial to perceive and react to dynamic environmental changes. Is motion perception processed also in a supramodal fashion? Furthermore, which is the effect of visual experience on the development of the functional architecture in motion responsive cortical regions? To investigate these questions, we compared brain responses in sighted and congenitally or early blind individuals during passive perception of visual and/or tactile motion (Ricciardi et al., 2007). Perception of dynamic stimuli in the visual and tactile sensory modalities shares fundamental psychophysical principles that can be explained by similar computational models. Both optic and tactile motion provide information about object form, position, orientation, consistency and movement, and also about the position and movement of the self in the environment (Bicchi et al., 2008). In sighted subjects, visual motion perception induced activation in the human middle temporal (hMT+) complex in the posterior inferior temporal cortex bilaterally, as expected on the basis of previous studies (Watson et al., 1993; Ptito et al., 2001a). In contrast, tactile motion perception activated the anterior part but deactivated a more posterior part of the hMT+ complex (Figure 3C). In blind subjects, tactile motion activated not only the anterior portion but also the more posterior part of the hMT+ complex, which was activated by visual motion and deactivated by tactile motion in sighted subjects (Figure 3D). In a separate study we demonstrated that repetitive TMS (rTMS) over the more anterior portion of hMT+ impairs the ability to detect changes in rotational velocity during a tactile motion discrimination task in blindfolded sighted subjects, indicating that recruitment of hMT+ is not a merely an epiphenomenon but it is truly necessary for tactile motion discrimination (Ricciardi et al., 2011).

\section{ROLE OF VISUAL EXPERIENCE ON THE FUNCTIONAL ARCHITECTURE OF THE hMT+ COMPLEX}

The observation that the hMT+ complex can be activated by tactile motion perception even in congenitally blind subjects demonstrates that recruitment of the hMT+ cortex is not mediated by visual-based mental imagery and that visual experience is not necessary for its development. Visual experience, however, does affect the functional architecture of hMT+ as it leads to the segregation of this region into a more anterior part, that is involved in the representation of both optic and tactile motion, and a more posterior part, that is uniquely involved in the representation of optic flow. When hMT+ develops in the absence of visual experience, the entire structure becomes involved in the representation of tactile motion. Moreover, hMT + develops different networks of connectivity with the rest of the brain in sighted and in congenitally blind individuals (Sani et al., 2010). These results suggest that competitive interactions between visual and tactile inputs lead to functional specialization within the hMT+ complex only under conditions of physiological development.

\section{THE hMT+ COMPLEX PROCESSES MOTION PER SE}

Activation of area hMT+ was also shown in both sighted and congenitally blind individuals while listening to auditory stimuli that elicit the apparent perception of sounds moving right-to-left, front-to-back, and self-rotating (Poirier et al., 2006; Ricciardi et al., 2006b). Moreover, area hMT+ in blindfolded sighted and blind subjects responded to motion stimuli applied to the tongue by the means of an electrotactile device (Matteau et al., 2010). These findings expand the data discussed above indicating that hMT+ 
can process information about motion that is not acquired through the visual sensory modality, including tactile and auditory flow. It follows that hMT+ is capable of processing motion-related information per se, even when motion stimuli are delivered to body structures, such as the tongue, that, at least in humans, are not primarily devoted to the perception of movement or spatial location (Matteau et al., 2010).

Altogether, the results of these studies strongly indicate that "visual" association cortical regions are capable of processing and interpreting information carried by non-visual sensory modalities. This is not merely the consequence of a phenomenon of plastic functional reorganization in the brain of subjects deprived of sight since birth or soon afterward, as this ability is also present in sighted subjects, suggesting that these cortical structures are supramodal in nature. Not surprisingly, however, sighted and congenitally blind individuals do show differences in the extension and magnitude of the activation of the recruited areas that are likely due to rearrangements that follow the lack of sight. The supramodal nature of this functional cortical organization may explain how individuals who have never had any visual experience are able to acquire normal knowledge about objects and their position in space, form mental representations of and interact effectively with the external world (Pietrini et al., 2004, 2009, Ricciardi et al., 2007; Fiehler et al., 2009).

\section{UNDERSTANDING WITHOUT SEEING: THE MIRROR NEURON SYSTEM IN BLIND SUBJECTS ACTION UNDERSTANDING}

Understanding actions carried out by other individuals is crucial for survival and for social organization in human and non-human primates. A particular class of neurons, discovered in the monkey premotor and parietal cortex, discharges both when performing a goal-directed action and when observing another individual performing the same action. These neurons have been named "mirror neurons” (Gallese et al., 1996; Rizzolatti et al., 1996; Rizzolatti and Fadiga, 1998; Rizzolatti and Craighero, 2004). The fact that this mirror neuron system is able to transform visual information into motor knowledge raises the hypothesis that this system may also play a significant role in action understanding. This has been confirmed by several animal studies showing that the mirror neuron system is also recruited when monkeys receive non-visual clues which allow them to understand the meaning, and create a mental representation of the occurring actions, such as when listening to action sounds (Kohler et al., 2002). In fact, a subclass of auditory-visual mirror neurons respond both while monkeys perform hand or mouth actions and while they listen to sounds of similar actions.

A similar "mirror" system has been identified in humans by using fMRI and is thought to play a major role not only in action and intention understanding, but also in learning by imitation, empathy, and language development (Buccino et al., 2004a,b; Rizzolatti and Craighero, 2004; Rizzolatti, 2005; Fabbri-Destro and Rizzolatti, 2008; Rizzolatti and Sinigaglia, 2008). The human mirror neuron system is activated during the observation of actions done by others and recruits a complex network formed by occipital, temporal, and parietal areas, and the inferior frontal cortex. As in non-human primates, the human mirror system is also recruited when individuals receive clues to understand the meaning of the occurring action with no access to visual features, such as when they only listen to the sound of actions (Gazzola et al., 2006; Lahav et al., 2007) or action-related sentences (Baumgaertner et al., 2007; Galati et al., 2008). These findings however do not address the question of whether activation within the mirror system in response to aurally presented stimuli may be mediated by sound-elicited visual imagery of the represented action or is rather independent from vision.

\section{HOW BLIND SUBJECTS “SEE" THE ACTION OF OTHERS}

We recently asked whether an efficient mirror neuron system exists in individuals who have never had any visual experience, and whether this action recognition-oriented network shares common neural patterns in sighted and blind individuals (Ricciardi et al., 2009). We measured neural response patterns in congenitally or early blind and sighted volunteers during the auditory presentation of hand-executed action or environmental sounds, and the motor pantomime of manipulation tasks. Sighted volunteers also performed an additional visual action recognition task. Congenitally blind individuals activated a premotor-temporo-parietal cortical network in response to aurally presented actions. This network overlapped both with mirror system areas found in sighted subjects in response to visually and aurally presented stimuli, and with the brain response patterns elicited by motor pantomime of the same actions (Figure 4). Furthermore, the mirror system showed a significantly larger response to familiar as compared to unfamiliar action sounds in both sighted and blind individuals (Ricciardi et al., 2009).

These findings indicate that visual experience is not a necessary precondition for the functional development of an efficient mirror neuron system, and suggest that a more abstract representation of actions by others also takes place through non-visual sensory modalities. This may contribute to explain the ability of congenitally blind individuals to learn by imitation of others.

\section{SEEING WITHOUT UNDERSTANDING: BLINDSIGHT}

In the preceding sections, we have shown that modifications of the input structures and alterations of the retino-recipient subcortical structures lead to a rearrangement of brain architecture. These altered brain structures can process sensory information and lead, in some instances, to quasi-normal behavioral functions. Our understanding of the mechanisms in recovery from large cortical lesions associated with brain plasticity is still unclear and remains an upmost challenge. With respect to vision, it remains difficult to explain in a satisfactory manner the remaining visual functions in patients with lesions restricted to the primary visual cortex (area V1) or with massive lesions encompassing the entire visual cortex of one hemisphere as in hemispherectomy. Destruction of area V1 has devastating effects and induces cortical blindness, i.e., a contralesional loss of the visual field (homonymous hemianopia). There is evidence that hemianopic human subjects and monkeys possess residual visual capacities in the blind part of their visual field (Cowey and Stoerig, 1995; Cowey, 2010). For example, in forced-choice paradigms where participants have to respond to stimuli presented in their blind field, performance is always above chance level 
A
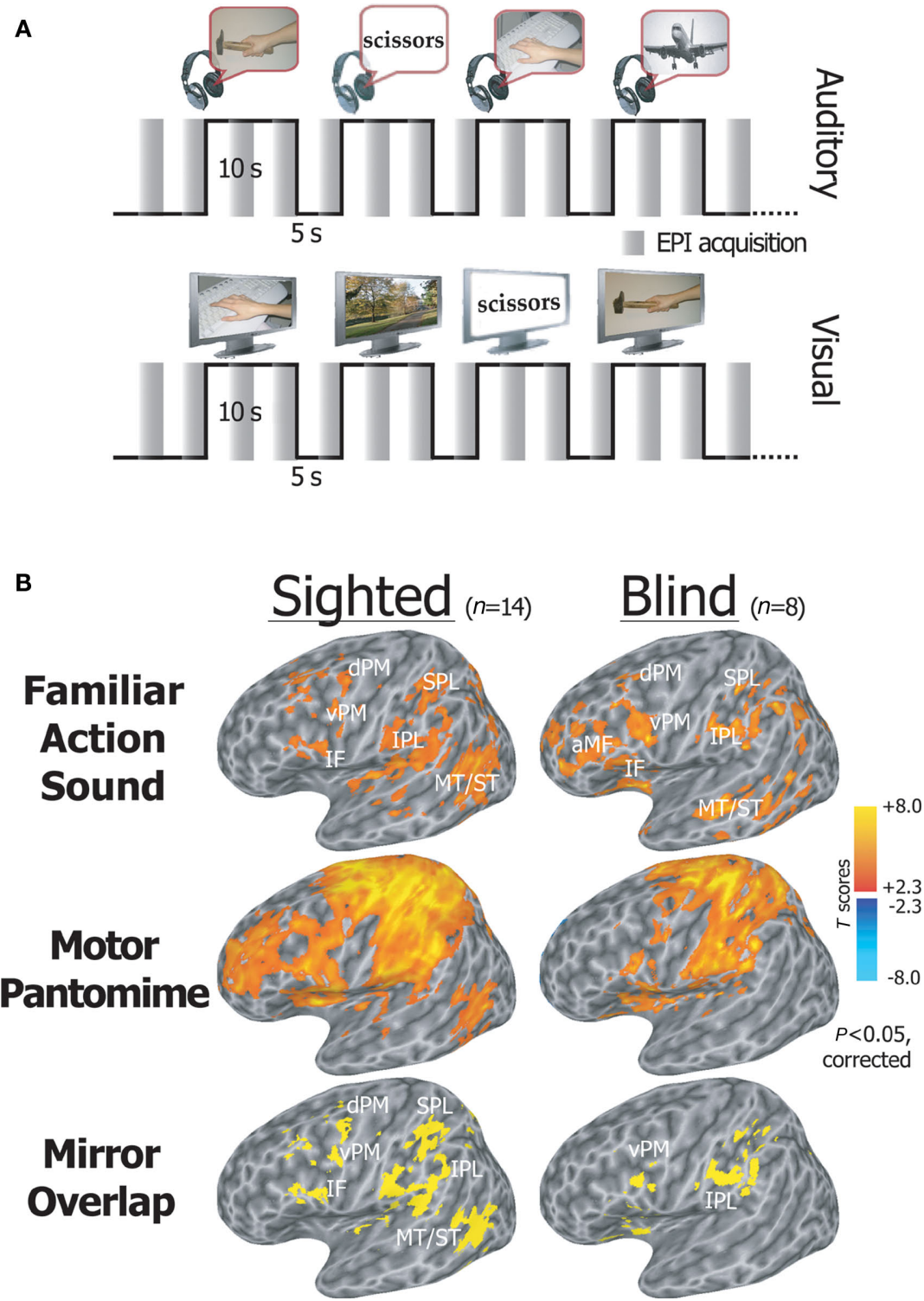

FIGURE 4 | Activation of the mirror system by action sounds. (A) fMRI experimental paradigm. An fMRI sparse sampling block design was used to examine neural activity in congenitally blind and sighted volunteers, while they alternated between the random presentation of hand-executed action or environmental sounds/movies, and the motor pantomime of a "virtual" tool or object manipulation task. (B) Statistical maps showing brain regions activated during listening to familiar action as compared to environmental sounds, and during the motor pantomime of action as compared to rest. Auditory mirror voxels are shown in yellow as overlap between the two task conditions (bottom row). Spatially normalized activations are projected onto a single-subject left hemisphere template in Talairach space. aMF, anterior middle frontal gyrus; IF, inferior frontal gyrus; vPM, ventral premotor cortex; dPM, dorsal premotor cortex; MT/ST, middle temporal and superior temporal cortex; IPL, inferior parietal lobule; SPL, superior parietal lobule (modified from Ricciardi et al., 2009). although subjects consistently deny having seen the stimulus. This lack of acknowledged awareness has been termed blindsight (Weiskrantz et al., 1974) and has received considerable attention within the neuroscience community. The preserved visual abilities that have been reported include target detection and localization by eye-movement or manual pointing, movement and direction detection, two-color discrimination, as well as relative velocity discrimination. These residual functions have been ascribed to the spared extrastriate cortices of the lesioned hemisphere that maintain "normal" anatomical connections with their subcortical targets (Cowey, 2010), though some claims that these residual abilities are due to the sparing of minimal portions of V1 cortex (Radoeva et al., 2008). There is recent evidence from fMRI studies in monkeys with V1 lesions that ascribe blindsight to extrastriate activation via a residual pathway from the LGN to the extrastriate visual cortex (Schmid et al., 2010). In agreement with this observation, we recently showed a direct functional connection between the thalamus and the hMT+ complex in humans, that would enable motion information to reach directly hMT+, thereby bypassing V1 (Gaglianese et al., 2010). 


\section{VISUAL AWARENESS FOLLOWING HEMISPHERECTOMY}

Hemispherectomy patients offer an alternative and unique model to study blindsight. In this condition, all the visual cortical areas of one hemisphere have been surgically removed, preventing the possibility that spared remnants of the visual cortex or extrastriate visual areas contribute to residual vision (Ptito and Leh, 2007). In addition, hemispherectomy allows for the investigation of the contribution of the remaining hemisphere through rewiring of the subcortical visual pathways. When hemispherectomized patients are asked to respond to a stimulus presented in their intact hemifield, they respond faster when an additional stimulus is presented at the same time in their blind hemifield, indicating a spatial summation effect, in spite of the fact that they are not aware that a stimulus was presented in the blind hemifield (Tomaiuolo et al., 1997). An fMRI study showed that these patients activate ipsilateral striate and extrastriate areas V3/V3A and V5 following stimulation of their blind hemifield (Bittar et al., 1999). In contrast, following stimulation of the intact hemifield, hemispherectomized patients activate the same brain areas in the contralateral hemisphere as normal sighted controls. Recent DTI studies revealed that the information originating in the blind hemifield is routed through the intercollicular commissure to the contralateral superior colliculus, then to the pulvinar to reach the visual cortex of the remaining hemisphere (Leh et al., 2006, 2008). These results are supported by neuroanatomical data showing a remarkable preservation of both superior colliculi in hemispherectomized monkeys (Théoret et al., 2001). The remaining hemisphere therefore seems to play a role in the implicit processing of visual information presented in the blind hemifield. If the primary visual cortex is necessary for visual consciousness, how can we explain that blindsight is still present in hemispherectomized patients?

\section{CONSCIOUS VERSUS UNCONSCIOUS PERCEPTS}

Models of conscious visual perception have evoked recurrent processing of visual information between visual cortical areas (Lamme, 2006) or a preconscious treatment of the activation within the visual areas (Dehaene et al., 2006). In both cases, the recruitment of fronto-parietal areas leads to a reportable conscious percept. Following selective damage of area V1, visual information from the blind hemifield is funneled directly to extrastriate cortical regions via subcortical structures (Cowey 2010; Schmid et al., 2010). We believe that in this case, the recurrent activation within the visual cortical areas is diminished to subliminal levels, leading to an unconscious percept (blindsight type I). The additional recruitment of the fronto-parietal network increases the activation level to threshold level, by recurrent activation, leading to visual awareness (blindsight Type II). In the case of hemispherectomy, the information from the blind field is transferred to the remaining hemisphere (Ptito and Leh, 2007) and the same recurrent activations might operate in the remaining hemisphere, explaining the two types of blindsight reported in these patients.

The same recurrent activation model of Lamme (2006) can also be applied to the condition of persistent vegetative state (PVS). For example, in PVS patients, sensory information stays confined to primary sensory cortex and is functionally uncoupled from activation in higher order association areas, including the posterior parietal cortex (Laureys et al., 2002). It is therefore plausible that recurrent activation processing does not occur, leaving the system in a subliminal state. This may explain why awake PVS patients may show basic visual functions such as eye movements and/or visual fixation without showing signs of visual consciousness (Owen et al., 2009; Bruno et al., 2010).

\section{SUBJECTIVE EXPERIENCE (QUALIA) ASSOCIATED WITH ACTIVATION OF THE VISUAL CORTEX}

As it has become clear from the studies described above, the occipital cortex in congenitally blind individuals is recruited by a wide variety of different types of sensory stimuli and cognitive tasks. It is generally accepted that cortical activity in a certain area produces a subjective sensation within the same domain. Thus, electrical stimulation experiments showed that stimulation of the somatosensory cortex (SI) induces tactile sensations referred to a particular body area. These stimulation studies further showed that the body is somatotopically mapped as inputs from neighboring body parts are encoded in adjacent parts within SI (Penfield and Boldrey, 1937). TMS is a technique that allows to stimulate the cortex in a non-invasive manner, either with the aim to interfere with brain activity within a specific brain area or to assess cortical excitability by evoking subjective sensations such as phosphenes or overt motor responses (Cowey and Walsh, 2000). For instance, the phosphene threshold is reduced after a brief period of blindfolding, indicating an increase in the excitability of the visual cortex (Boroojerdi et al., 2000). In view of the earlier described cross-modal responses in the occipital cortex of the blind, the question arises which type of sensations will be induced when applying TMS over the occipital cortex in these subjects. Studies in rewired ferrets seem to suggest that activation in the auditory cortex may be perceived as visual and not as auditory (von Melchner et al., 2000). We addressed this question in a series of studies (Kupers et al., 2006; Ptito et al., 2008a). In a first study, we exploited a tactile-to-vision sensory substitution model to examine the subjective character of experience associated with the activation of occipital cortex before and after the establishment of cross-modal plasticity (Kupers et al., 2006). More specifically, we wanted to test whether stimulation of the occipital cortex induces subjective sensations associated with the new (tactile) input. Thereto, we applied TMS over the occipital cortex before and after training with the tongue display unit (TDU) in a group of congenitally blind and blindfolded sighted control subjects. The TDU is a sensory substitution device that captures a visual image, taken by a camera or generated on a computer, and translates it into electrotactile pulses which are applied to the tongue (Bach-y-Rita and Kercel, 2003). With training, subjects learn to use the TDU to perform basic visual tasks such as orientation discrimination, motion and form detection, and spatial navigation. Our results showed that the effects of TMS depend on group and training. Before training, TMS of the occipital cortex elicited phosphenes in control subjects but not in blind subjects, which is in line with earlier findings (Cowey and Walsh, 2000). In sharp contrast, following 1 week of training, occipital TMS-induced "tactile sensations" on the tongue in blind subjects, which were described as short-lasting experiences of distinct tingling, varying in intensity, extent, and topography depending on the locus of the occipital cortex which was stimulated (Figure 5A). The number of occipital sites from which TMS-induced tactile sensations could be induced correlated significantly with 
the size of occipital cortex that blind participants activated during a sensory substitution task with the TDU, as measured with PET (Kupers et al., 2006). None of the trained blindfolded subjects reported TMS-induced tactile sensations on the tongue.
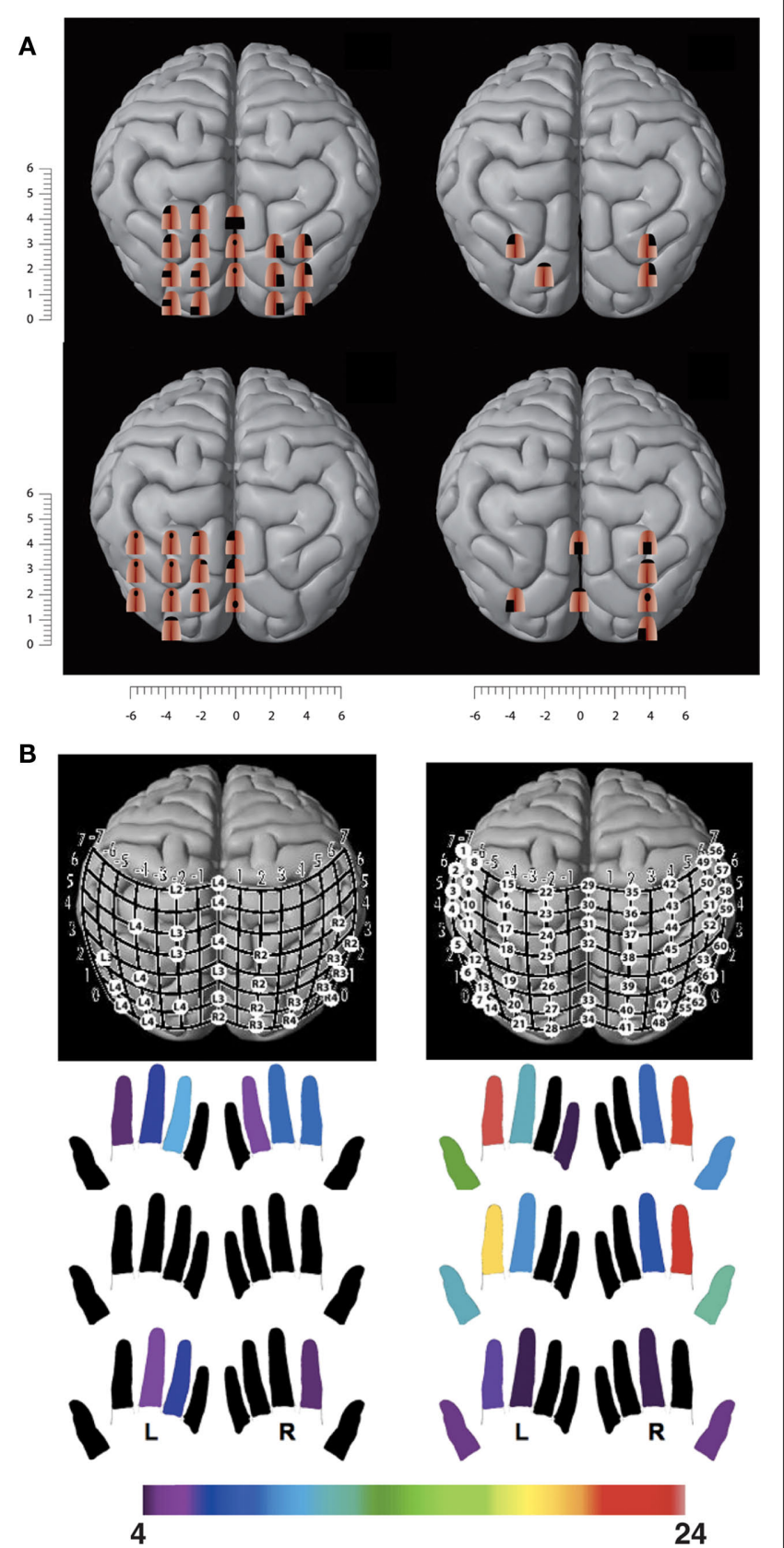

FIGURE 5 |TMS of the visual cortex in congenitally blind subjects induces tactile sensations. (A) TMS-induced tactile sensations referred to the tongue in congenitally blind subjects following a 1-week training with the TDU. (B) TMS-induced tactile sensations referred to the fingertips in two congenitally blind proficient Braille readers. The color map below indicates the fingers in which the subject experiencedTMS-induced tactile sensations. The number of visual cortex sites from which paresthesiae could be induced in a particular finger is color-coded, with red indicating the highest number of cortical sites that induced paresthesiae in a particular finger and purple the lowest number (adapted after Kupers et al., 2006; Ptito et al., 2008a).
If tactile sensations referred to the tongue can be induced by TMS of the occipital cortex in blind subjects trained for only 1 week with the TDU, TMS should also induce tactile sensations referred to the fingertips in proficient blind Braille readers. We addressed the question of remapping of the fingers onto the visual cortex in a group of blind Braille readers and Braille-naive normal sighted controls (Ptito et al., 2008a). Again, TMS of the occipital cortex in control subjects only evoked phosphenes. In contrast, blind subjects reported tactile sensations in the fingers, varying in intensity, extent, and topography depending on the stimulated occipital area (Figure 5B). We found again important inter-individual differences with respect to the number of sites from which tactile sensations could be induced and in the topography of the referred sensations. The subject with the highest amount of finger paresthesiae was the one with the best Braille reading performance.

\section{CORTICAL DOMINANCE AND CORTICAL DEFERENCE}

The results of these TMS studies constitute the first direct demonstration that the subjective experience of activity in the visual cortex after sensory remapping is tactile, not visual. These findings provide new insights into the long-established scientific debate on cortical dominance or deference (James, 1890; Hurley and Noë, 2003). What is the experience of a subject in whom areas of cortex receive input from sensory sources not normally projecting to those areas? Our studies suggest that the qualitative character of the subject's experience is not determined by the area of cortex that is active (cortical dominance), but by the source of input to it (cortical deference). Our results are in line with evidence that sensory cortical areas receive input from multiple sensory modalities early in development (Falchier et al., 2002; Rockland and Ojima, 2003; Wallace et al., 2004).

\section{CORTICAL REORGANIZATION OR UNMASKING?}

Two competing hypotheses have been put forward to explain the neural mechanism driving this cross-modal plasticity. According to the cortical reorganization hypothesis, cross-modal brain responses are mediated by the formation of new pathways in the sensorydeprived brain. Studies in animals have shown that when the brain is deprived of visual input at an early age, tactile and other nonvisual information is re-routed to the visual cortex (e.g., Hyvarinen et al., 1991; Chabot et al., 2008). This claim is largely supported by results of functional brain imaging studies showing activation of visual cortex in early blind subjects during Braille reading (Sadato et al., 1996; Burton et al., 2002) and other forms of tactile stimulation (Burton et al., 2004; Ptito et al., 2005). The importance of visual deprivation in early life is underscored by the observation that brain activity patterns in occipital cortex evoked by tactile stimulation are significantly stronger in early blind compared to late blind subjects (Cohen et al., 1999; Burton et al., 2002). According to the unmasking hypothesis, loss of a sensory input induces unmasking and strengthening of existing neuronal connections. The rapid onset of cross-modal responses with the TDU (within 1 week) excludes indeed the possibility that these are mediated by the establishment of new anatomical connections and therefore favors the unmasking hypothesis. One possibility is that training unmasks and strengthens pre-existing connections between the parietal and the occipital cortices. This claim is supported by 
electrophysiological (Fishman and Michael, 1973) and anatomical (Falchier et al., 2002; Rockland and Ojima, 2003) data showing that primary visual cortex in normal mammals receives input not only from the visual thalamus, but also from somatosensory and auditory modalities. Single unit recordings in the cat visual cortex have shown that neurons in areas 17 and 18 receive both visual and auditory input (Fishman and Michael, 1973). In addition, there is evidence for direct projections from the auditory cortex to area 17 in the macaque monkey (Falchier et al., 2002). There are also direct projections from parietal association areas to areas V1 and V2 in the calcarine fissure (Rockland and Ojima, 2003). Under normal circumstances, these non-visual inputs conveying tactile and auditory inputs to occipital cortex can modulate the processing of visual information (Macaluso et al., 2000), while not giving rise to subjective non-visual sensations due to masking by the dominant visual input. This is illustrated by a study showing that TMS over the visual cortex impairs tactile discrimination of grating orientation in normal seeing subjects, without producing subjective tactile sensations (Zangaladze et al., 1999). Thus, in our trained control subjects, TMS over occipital cortex produced phosphenes and not tactile sensations. However, under certain circumstances such as following early visual deprivation, non-visual processing in the occipital cortex is strengthened or unmasked. In line with the dynamic sensorimotor hypothesis, training with the TDU results in new highly specific learned dynamic interaction patterns between sensory stimulation and active movement (O'Regan and Noë, 2001), thereby further strengthening and unmasking existing connections between the parietal and occipital cortices.

\section{A DARWINIAN STRUGGLE FOR SURVIVAL?}

There is now a wealth of data showing that the occipital cortex in the blind is activated in a variety of tasks, including lexical and phonological processing (Röder et al., 2002; Burton et al., 2003; Amedi et al., 2004), verbal memory (Burton et al., 2003; Raz et al., 2005), repetition priming (Kupers et al., 2007), auditory discrimination (Röder et al., 1999; Weeks et al., 2000; Gougoux et al., 2005), selective attention (Stevens et al., 2007), working memory (Pietrini et al., 2004; Bonino et al., 2008), motion detection (Ricciardi et al., 2007), and spatial navigation (Kupers et al., 2010). How to interpret this multiplicity of sensory and cognitive functions of the occipital cortex in the blind? Does it reflect some kind of Darwinian principle of struggle for survival? As humans, we are living in a world in which vision has a central role. This is already reflected by the fact that the visual cortex in primates covers about $30 \%$ of the total cortical surface. Therefore, the loss of vision is one of the most incapacitating events that can occur to a person. In order to survive, blind subjects need to rely on other senses and develop these in a supranormal manner to compensate for their loss of vision. Functional brain imaging studies have shown that enhanced practice leads to an enlargement of cortical representations (Gaser and Schlaug, 2003; Draganski et al., 2004; Scholz et al., 2009). In the sighted brain, this results in an enlargement of the cortex that is normally involved in the execution of the task (e.g., an expansion of the motor cortex in musicians; Lotze et al., 2003; Bengtsson et al., 2005) and not by the recruitment of novel cortex. In contrast, in the case of loss of a sensory input, the brain recruits de novo cortex that is normally not involved in execution of that particular task. This may represent a Darwinian mechanism for survival. Recruitment of the visually deprived occipital cortex is a much more cost-effective computational solution since it does not put extra demands on the cortex which is normally used for executing that task, thereby leaving sufficient resources available for situations of increased demand. The pathways through which this occurs are available since birth but, in the sighted brain, the activity is masked by the dominant specific afferent input to a particular cortical region.

How does the rewired cortex cope with this multitude of new inputs? Is there some kind of segregation of functions or does the visually deprived cortex become genuinely multimodal? It is difficult to answer this question since most studies only investigated one or at best two different sensory modalities or cognitive functions in the same subjects. One of the first studies that investigated the cortical representation of multiple cognitive functions in the occipital cortex of the blind suggested that different functions are indeed segregated anatomically (Amedi et al., 2003). In contrast, a more recent study reported overlap of auditory and tactile information in the occipital cortex of early blind subjects (Renier et al., 2010). However, the right middle occipital gyrus showed a preference for spatial over non-spatial processing of both auditory and tactile stimuli. More studies are needed to resolve this issue.

\section{FINAL CONSIDERATIONS}

Animal and human studies of the dark-reared brain have shed new light on many questions regarding not only the plastic rearrangements that take place in the absence of vision but also on the development of the functional architecture of the sighted brain itself. The availability of methodologies for the non-invasive functional exploration of the brain has made it possible to begin to understand the neural mechanisms that enable awareness of the surrounding world and to make sense of it. The main hypothesis that we have put forward here is that the development of consciousness in the absence of vision is made possible through the supramodal nature of functional cortical organization. The more abstract representation of the concepts of objects, space, motion, gestures, and actions - in one term, awareness of the external world - is associated with regional brain activation patterns that are essentially similar in sighted and congenitally blind individuals (Pietrini et al., 2004, 2009). The morphological and/ or functional differences that exist between the sighted and the blind brain are the consequence of the cross-modal plastic reorganization that mostly affects that part of the cortex that is not multimodal in nature.

We would also like to acknowledge that the issues that we have considered are only a few among the many more that an ambitious topic such as the relation between blindness and consciousness may raise. For instance, we did not discuss the effects of congenital blindness versus blindness acquired at different ages, or the effects of monocular vision (Vecchi et al., 2006). Moreover, we have only briefly touched upon the "blind social brain," not to mention emotional life and its disturbances.

A final important thought prompted by the many different findings from studies in animal and humans is that the blind brain should not be considered as a "disabled" brain but rather as a truly "differentially able" brain. 


\section{ACKNOWLEDGMENTS}

Studies reported in this paper have been supported by grants from the following foundations and granting agencies: the Lundbeck Foundation (to Ron Kupers), the European Union (Grant IST-2001-38040 and IST-2006-027141 to Pietro Pietrini), the Italian Ministry of Education, University and Research (PRIN RBNE018ET9-003, 200411841, and 2006117208 to Pietro Pietrini),

\section{REFERENCES}

Amedi, A., Floel, A., Knecht, S., Zohary, E., and Cohen, L. G. (2004). Transcranial magnetic stimulation of the occipital pole interferes with verbal processing in blind subjects. Nat. Neurosci. 7, 1266-1270.

Amedi, A., Jacobson, G., Hendler, T., Malach, R., and Zohary, E. (2002). Convergence of visual and tactile shape processing in the human lateral occipital complex. Cereb. Cortex 12, 1202-1212.

Amedi, A., Malach, R., Hendler, T., Peled, S., and Zohary E. (2001). Visuo-haptic object-related activation in the ventral visual pathway. Nat. Neurosci. 4, 324-330.

Amedi, A., Raz, N., Pianka, P., Malach, R., and Zohary, E. (2003). Early 'visual' cortex activation correlates with superior verbal memory performance in the blind. Nat. Neurosci. 6, 758-766.

Bach-y-Rita, P., and Kercel, S. (2003). Sensory substitution and the humanmachine interface. Trends Cogn. Sci. 7, 541-546.

Baumgaertner, A., Buccino, G., Lange, R., McNamara, A., and Binkofski, F. (2007). Polymodal conceptual processing of human biological actions in the left inferior frontal lobe. Eur. J. Neurosci. 25, 881-889.

Bengtsson, S. L., Nagy, Z., Skare, S., Forsman, L., Forssberg, H., and Ullén, F. (2005). Extensive piano practicing has regionally specific effects on white matter development. Nat. Neurosci. 8 , 1148-1150.

Bicchi, A., Scilingo, E. P., Ricciardi, E., and Pietrini, P. (2008). Tactile flow explains haptic counterparts of common visual illusions. Brain Res. Bull. 75, 737-741.

Bittar, R. G., Ptito, M., Faubert, J., Dumoulin, S. O., and Ptito, A. (1999). Activation of the remaining hemisphere following stimulation of the blind hemifield in hemispherectomized subjects. Neuroimage 10, 3339-3346.

Bonino, D., Ricciardi, E., Sani, L., Gentili, C., Vanello, N., Guazzelli, M., Vecchi, T., and Pietrini, P. (2008). Tactile spatial working memory activates the dorsal extrastriate cortical pathway in congenitally blind individuals. Arch. Ital. Biol. 146, 133-146.

Boroojerdi, B., Bushara, K. O., Corwell, B., Immisch, I., Battaglia, F., Muellbacher,
W., and Cohen, L. G. (2000). Enhanced excitability of the human visual cortex induced by short-term light deprivation. Cereb. Cortex 10, 529-534.

Bronchti, G., Heil, P., Sadka, R., Hess, A., Scheich, H., and Wollberg, Z. (2002). Auditory activation of "visual" cortical areas in the blind mole rat (Spalax ehrenbergi). Eur. J. Neurosci. 16, 311-329.

Bruno, M. A., Vanhaudenhuyse, A., Schnakers, C., Boly, M., Gosseries, O., Demertzi, A., Majerus, S., Moonen, G., Hustinx, R., and Laureys, S. (2010). Visual fixation in the vegetative state: an observational case series PET study. BMCNeurol. 10:35. doi: 10.1186/14712377-10-35

Buccino, G., Binkofski, F., and Riggio, L. (2004a). The mirror neuron system and action recognition. Brain Lang. 89, 370-376.

Buccino, G., Vogt, S., Ritzl, A., Fink, G. R., Zilles, K., Freund, H. J., and Rizzolatti, G. (2004b). Neural circuits underlying imitation learning of hand actions: an event-related fMRI study. Neuron 42 , 323-334.

Burton, H., Diamond, J. B., and McDermott, K. B. (2003). Dissociating cortical regions activated by semantic and phonological tasks: a FMRI study in blind and sighted people. $J$. Neurophysiol. 90, 1965-1982.

Burton, H., Sinclair, R. J., and McLaren, D. G. (2004). Cortical activity to vibrotactile stimulation: an fMRI study in blind and sighted individuals. Hum. Brain Mapp. 23, 210-228.

Burton, H., Snyder, A. Z., Conturo, T. E., Akbudak, E., Ollinger, J. M., and Raichle, M.E. (2002). Adaptive changes in early and late blind: a fMRI study of Braille reading. J. Neurophysiol. 87, 589-607.

Cattaneo, Z., Vecchi, T., Cornoldi, C., Mammarella, I., Bonino, D., Ricciardi, E., and Pietrini P. (2008). Imagery and spatial processes in blindness and visual impairment. Neurosci. Biobehav. Rev. 32, 1346-1360.

Chabot, N., Charbonneau, V., Laramée, M. E., Tremblay, R., Boire, D., and Bronchti, G. (2008). Subcortical auditory input to the primary visual cortex in anophthalmic mice. Neurosci. Lett. 433, 129-134.

Chebat, D. R., Rainville, C., Kupers, R., and Ptito, M. (2007). Alterations in

Fondazione IRIS, Castagneto Carducci (Livorno, Italy to Pietro Pietrini), the Danish Medical Research Council (to Maurice Ptito), and the Harland Sanders Foundation (to Maurice Ptito). Pietro Pietrini and Emiliano Ricciardi wish to thank the Unione Italiana Ciechi for its support to the blindness research program, and the MRI Laboratory at the Fondazione "Gabriele Monasterio" Regione Toscana/CNR (Pisa, Italy).

right posterior hippocampus in early blind individuals. Neuroreport 18, 329-333.

Cohen, L. G., Weeks, R. A., Sadato, N., Celnik, P., Ishii, K., and Hallett, M. (1999). Period of susceptibility for cross-modal plasticity in the blind. Ann. Neurol. 45, 451-460.

Cowey, A. (2010). The blindsight saga. Exp. Brain Res. 200, 3-24.

Cowey, A., and Stoerig, P. (1995) Blindsight in monkeys. Nature 373, 247-249.

Cowey, A., and Walsh, V. (2000). Magnetically induced phosphenes in sighted, blind and blindsighted observers. Neuroreport 11, 3269-3273.

Dehaene, S., Changeux, J. P., Naccache, L., Sackur, J., and Sergent, C. (2006). Conscious, preconscious, and subliminal processing: a testable taxonomy. Trends Cogn. Sci. 10, 204-211.

Desgent, S., Boire, D., and Ptito, M. (2005). Distribution of calcium binding proteins in visual and auditory cortices of hamsters. Exp. Brain Res. 163, 159-172.

Desgent, S., Boire, D., and Ptito, M. (2010) Altered expression of parvalbumin and calbindin in interneurons within the primary visual cortex of neonatal enucleated hamsters. Neuroscience. doi: 10.1016/j.neuroscience.2010.10.016 [Epub ahead of print]

Draganski, B., Gaser, C., Busch, V., Schuierer, G., Bogdahn, U., and May, A. (2004). Neuroplasticity: changes in grey matter induced by training. Nature 427, 311-312.

Fabbri-Destro, M., and Rizzolatti, G. (2008). Mirror neurons and mirror systems in monkeys and humans. Physiology (Bethesda) 23, 171-179.

Falchier, A., Clavagnier, S., Barone, P., and Kennedy, H. (2002). Anatomical evidence of multimodal integration in primate striate cortex. J. Neurosci. 22, 5749-5759.

Fiehler, K., Burke, M., Bien, S., Röder B., and Rösler, F. (2009). The human dorsal action control system develops in the absence of vision. Cereb. Cortex 19, 1-12.

Fishman, M. C., and Michael, P. (1973). Integration of auditory information in the cat's visual cortex. Vision Res. 13, 1415-1419.

Fortin, M., Voss, P., Lord, C., Lassonde, M., Pruessner, J., Saint-Amour, D., Rainville, C., and Lepore, F. (2008).
Wayfinding in the blind: larger hippocampal volume and supranormal spatial navigation. Brain 131, 2995-3005.

Frost, D. O., Boire, D., Gingras, G., and Ptito, M. (2000). Surgically created neural pathways mediate visual pattern discrimination. Proc. Natl. Acad. Sci. U.S.A. 97, 11068-11073.

Frost, D. O., and Metin, C. (1985). Induction of functional retinal projections to the somatosensory system. Nature 317, 162-164.

Fujii, T., Tanabe, H.C., Kochiyama, T., and Sadato, N. (2009). An investigation of cross-modal plasticity of effective connectivity in the blind by dynamic causal modeling of functional MRI data. Neurosci. Res. 65, 175-186.

Gaglianese, A., Sani, L., Roebroeck, A., Handjaras, G., Bernardi, G., Costagli, M., Ricciardi, E., and Pietrini, P. (2010). "fMRI functional and effective connectivity in humans supports a direct pathway from thalamus to $\mathrm{hMT}+$," in Presented at the 16th Annual Meeting of the Organization for Human Brain Mapping, Barcelona.

Galati, G., Committeri, G., Spitoni, G., Aprile, T., Di Russo, F., Pitzalis, S., and Pizzamiglio, L. (2008). A selective representation of the meaning of actions in the auditory mirror system. Neuroimage 40, 1274-1286.

Gallese, V., Fadiga, L., Fogassi, L., and Rizzolatti, G. (1996). Action recognition in the premotor cortex. Brain 119 , 593-609.

Gaser, C., and Schlaug, G. (2003). Brain structures differ between musicians and non-musicians. J. Neurosci. 23, 9240-9245.

Gauthier, I., Skudlarski, P., Gore, J. C., and Anderson, A. W. (2000). Expertise for cars and birds recruits brain areas involved in face recognition. Nat. Neurosci. 3, 191-197.

Gauthier, I., Tarr, M. J., Anderson, A. W., Skudlarski, P., and Gore, J. C. (1999). Activation of the middle fusiform 'face area' increases with expertise in recognizing novel objects. Nat. Neurosci. 2, 568-573.

Gazzola, V.,Aziz-Zadeh, L., and Keysers, C. (2006). Empathy and the somatotopic auditory mirror system in humans. Curr. Biol. 16, 1824-1829.

Gougoux, F., Zatorre, R. J., Lassonde, M., Voss, P., and Lepore, F. (2005). A func- 
tional neuroimaging study of sound localization: visual cortex activity predicts performance in early-blind individuals. PLoS Biol. 3, e27. doi: 10.1371/j.pbio.0030027

Haxby, J. V., Gobbini, M. I., Furey, M. L., Ishai, A., Schouten, J. L., and Pietrini, P. (2001). Distributed and overlapping representations of faces and objects in ventral temporal cortex. Science 293, 2425-2430.

Haxby, J. V., Horwitz, B., Ungerleider, L., Maisog, J. M., Pietrini, P., and Grady, C. L. (1994). The functional organization of human extrastriate cortex: a PET-rCBF study of selective attention to faces and locations. J. Neurosci. 14, 6336-6353.

Hurley, S. L., and Noë, A. (2003). Neural plasticity and consciousness. Biol. Philos. 18, 131-168.

Hyvarinen, J., Hyvärinen, L., and Linnankoski, I. (1991). Modification of parietal association cortex and functional blindness after binocular deprivation in young monkeys. Exp. Brain Res. 42, 1-8.

Ishai, A. (2010). Seeing faces and objects with the "mind's eye". Arch. Ital. Biol. 148, 1-9.

Ishai, A., Ungerleider, L. G., and Haxby, J. V. (2000). Distributed neural systems for the generation of visual images. Neuron 28, 979-990.

Ishai, A., Ungerleider, L. G., Martin, A., Schouten, J. L., and Haxby, J. V. (1999). Distributed representation of objects in the human ventral pathway. Proc. Natl. Acad. Sci. U.S.A. 96, 9379-9384.

James, T. W., Humphrey, G. K., Gati, J. S., Servos, P., Menon, R. S., and Goodale, M. A. (2002). Haptic study of threedimensional objects activates extrastriate visual areas. Neuropsychologia 40, 1706-1714.

James, W. (1890). Principles of Psychology. New York: Dover.

Kanwisher, N., McDermott, J., and Chun, M. M. (1997). The fusiform face area: a module in human extrastriate cortex specialized for face perception. $J$. Neurosci. 17, 4302-4311.

Klinge, C., Eippert, F., Röder, B., and Büchel, C. (2010). Corticocortical connections mediate primary visual cortex responses to auditory stimulation in the blind. J. Neurosci. 30, 12798-12805.

Kohler, E., Keysers, C., Umilta, M. A., Fogassi, L., Gallese, V., and Rizzolatti, G. (2002). Hearing sounds, understanding actions: action representation in mirror neurons. Science 297, 846-848.

Kupers, R., Chebat, D. R., Madsen, K. H., Paulson, O. B., and Ptito, M. (2010). Neural correlates of virtual route recognition in congenital blindness.
Proc. Natl. Acad. Sci. U.S.A. 107, 12716-12721.

Kupers, R., Christensen, R., Grey, M., and Ptito, M. (2009). Glucose metabolism of the occipital cortex in early blind subjects. Soc. Neurosci. Abstr. 167.26.

Kupers, R., Fumal, A., de Noordhout, A. M., Gjedde, A., Schoenen, J., and Ptito, M. (2006). Transcranial magnetic stimulation of the visual cortex induces somatotopically organized qualia in blind subjects. Proc. Natl. Acad. Sci. U.S.A. 103, 13256-13260.

Kupers, R., Pappens, M., Ptito, M., and Fumal, A. (2007).rTMS of the occipital cortex abolishes Braille reading and repetition priming in blind subjects. Neurology 68, 691-693.

Lahav, A., Saltzman, E., and Schlaug, G. (2007). Action representation of sound: audiomotor recognition network while listening to newly acquired actions. J. Neurosci. 27, 308-314.

Lamme, V.A. (2006). Towards a true neural stance on consciousness. Trends Cogn. Sci. 10, 494-501.

Laureys, S., Faymonville, M. E., Peigneux, P., Damas, P., Lambermont, B., Del Fiore, G., Degueldre, C., Aerts, J., Luxen, A., Franck, G., Lamy, M., Moonen, G., and Maquet, P. (2002). Cortical processing of noxious somatosensory stimuli in the persistent vegetative state. Neuroimage 17, 732-741.

Leh, S. E., Chakravarty, M. M., and Ptito, A. (2008). The connectivity of the human pulvinar: a diffusion tensor imaging tractography study. Int. J. Biomed. Imaging. doi 10.11555/2008/789539

Leh, S. E., Johansen-Berg, H., and Ptito, A. (2006). Unconscious vision: new insights into the neuronal correlate of blindsight using diffusion tractography. Brain 129, 1822-1832.

Lotze, M., Scheler, G., Tan, H. R. M., Braun, C., and Birbaumer N. (2003). The musician's brain: functional imaging of amateurs and professionals during performance and imagery. Neuroimage 20, 1817-1829.

Lyckman, A. W., and Sur, M. (2002). Role of afferent activity in the development of cortical specification. Results Probl. Cell Differ. 39, 139-156.

Macaluso, E., Frith C. D., and Driver. J. (2000). Modulation of human visual cortex by crossmodal spatial attention. Science 289, 1206-1208.

Matteau, I., Kupers, R., and Ptito, M. (2008). Tactile shape recognition through the tongue in the congenitally blind. FENS. Abstr 2008; 4:153.8.p.83

Matteau, I., Kupers, R., Ricciardi, E., Pietrini, P., and Ptito, M. (2010). Beyond visual, aural and haptic movement perception: hMT+ is activated by electrotactile motion stimulation of the tongue in sighted and in congenitally blind individuals. Brain Res. Bull. 82, 264-270.

McCarthy, G., Puce, A., Gore, J. C., and Allison, T. (1997). Face-specific processing in the human fusiform gyrus. J. Cogn. Neurosci. 9, 605-610.

Merabet, L. B., and Pascual-Leone, A. (2010). Neural reorganization following sensory loss: the opportunity of change. Nat. Rev. Neurosci. 11, 44-52.

Metin, C., and Frost, D. O. (1989). Visua responses of neurons in somatosensory cortex of hamsters with experimentally induced retinal projections to somatosensory thalamus. Proc. Natl. Acad. Sci. U.S.A. 86, 357-361.

Noppeney, U., Friston, K. J., Ashburner, J., Frackowiak, R., and Price, C. J. (2005). Early visual deprivation induces structural plasticity in gray and white matter. Curr. Biol. 15, 488-490.

O'Craven, K. M., and Kanwisher, N. (2000). Mental imagery of faces and places activates corresponding stimulus-specific brain regions. J. Cogn. Neurosci. 12, 1013-1023.

O'Regan, J. K., and Noë, A. (2001). A sensorimotor account of vision and visual consciousness. Behav. Brain Sci. 24, 939-973.

Owen, A. M., Schiff, N. D., and Laureys, S. (2009). "The assessment of conscious awareness in the vegetative state," in The Neurology of Consciousness, eds S. Laureys and G. Tononi (London: Academic Press), 163-172.

Pallas, S. L. (2001). Intrinsic and extrinsic factors that shape neocortical specification. Trends Neurosci. 24, 417-423.

Pallas, S. L. (2002). “Cross-modal plasticity as a tool for understanding the ontogeny and phylogeny of cerebral cortex," in Cortical Areas: Unity and Diversity, eds A. Schuz and R. Miller (London/ New York: Taylor and Francis Inc.), 245-271.

Pan, W. J., Wu, G., Li, C. X., Lin, F., Sun, J., and Lei, H. (2007). Progressive atrophy in the optic pathway and visual cortex of early blind Chinese adults: a voxel-based morphometry magnetic resonance imaging study. Neuroimage 37, 212-220.

Penfield, W., and Boldrey, E. (1937) Somatic motor and sensory representation in the cerebral cortex of man as studied by electrical stimulation. Brain 60, 389-443.

Pietrini, P., Furey, M. L., Ricciardi, E., Gobbini, M. I., Wu, W. H., Cohen, L., and Guazzelli, M. Haxby, J. V. (2004). Beyond sensory images: object-based representation in the human ventral pathway. Proc. Natl. Acad. Sci. U.S.A. 101, 5658-5663.

Pietrini, P., Ptito, M., and Kupers, R. (2009). "Blindness and conscious- ness: new lights from the dark," in The Neurology of Consciousness, eds S. Laureys and G. Tononi (New York: Academic Press), 360-374.

Poirier, C., Collignon, O., Scheiber, C., Renier, L., Vanlierde, A., Tranduy, D. Veraart, C., and DeVolder,A.G. (2006). Auditory motion perception activates visual motion areas in early blind subjects. Neuroimage 31, 279-285.

Ptito, A., and Leh, S. E. (2007). Neural substrates of blindsight after hemispherectomy. Neuroscientist 13, 506-518.

Ptito, M., and Desgent, S. (2006). "Sensory input-based adaptation andbrain architecture," in Lifespan Development and the Brain, eds P. Baltes, P. Reuter-Lorenz, and F. Rösler (Cambridge University Press), 111-123.

Ptito, M., Fumal,A., de Noordhout, A. M., Schoenen, J., Gjedde, A., and Kupers, R. (2008a). TMS of the occipital cortex induces tactile sensations in the fingers of blind Braille readers. Exp. Brain Res. 184, 193-200.

Ptito, M., Schneider, F., Paulson, O. B., and Kupers, R. (2008b). Alterations of the visual pathways in congenital blindness. Exp. Brain Res. 87, 41-49.

Ptito, M., Giguère, J. F., Boire, D., Frost, D. O., and Casanova, C. (2001a). When the auditory cortex turns visual. Prog. Brain Res. 134, 447-458.

Ptito, M., Kupers, R., Faubert, J., and Gjedde, A. (2001b). Cortical representation of inward and outward radial motion in man. Neuroimage 14, 1409-1415.

Ptito, M., Moesgaard, S., Gjedde, A., and Kupers, R. (2005). Cross-modal plasticity revealed by electrotactile stimulation of the tongue in the congenitally blind. Brain 128, 606-614.

Radoeva, P. D., Prasad, S., Brainard, D. H., and Aguirre, G. K. (2008). Neural activity within area $\mathrm{vl}$ reflects unconscious visual performance in a case of blindsight. J. Cogn. Neurosci. 20, 1927-1939.

Raz, N., Amedi, A., and Zohary, E. (2005). V1 activation in congenitally blind humans is associated with episodic retrieval. Cereb. Cortex 15, 1459-1468.

Raz, N., Striem, E., Pundak, G., Orlov, T., and Zohary, E. (2007). Superior serial memory in the blind: a case of cognitive compensatory adjustment. Curr. Biol. 17, 1129-1133.

Rebillard, G., Carlier,E., Rebillard, M., and Pujol, R. (1977). Enhancement of visual responses on the primary auditory cortex of the cat after an early destruction of cochlear receptors. Brain Res. 129, 162-164.

Renier, L. A., Anurova, I., De Volder, A. G., Carlson, S., VanMeter, J., and Rauschecker, J. P. (2010). Preserved functional specialization for spatial 
processing in the middle occipital gyrus of the early blind. Neuron 68 , 138-148.

Ricciardi, E., Basso, D., Sani, L., Bonino, D., Vecchi, T., Pietrini, P., and Miniussi, C. (2011). Functional inhibition of the human MT+ cortex affects non-visual motion perception: a repetitive transcranial magnetic stimulation study during tactile speed discrimination. Exp. Biol. Med. 236. (in press).

Ricciardi, E., Bonino, D., Gentili, C., Sani, L., Pietrini, P., and Vecchi, T. (2006a). Neural correlates of spatial working memory in humans: a functional magnetic resonance imaging study comparing visual and tactile processes. Neuroscience 139, 339-349.

Ricciardi, E., Sani, L., Gentili, C., Bonino, D., Vanello, N., Haxby, J.V., Seifritz, E., Guazzelli, M., Landini, L., Bicchi, A., Di Salle, F., and Pietrini, P. (2006b). Brain response to visual, tactile and auditory flow in sighted and blind individuals supports a supramodal functional organization in hMT+ complex. Neuroimage 31(Suppl. 1), 512 TH-PM.

Ricciardi, E., Bonino, D., Sani, L., Vecchi, T., Guazzelli, M., Haxby, J. V., Fadiga, L., and Pietrini, P. (2009). Do we really need vision? How blind people "see" the actions of others. J. Neurosci. 29, 9719-9124.

Ricciardi, E., Vanello, N., Sani, L., Gentili, C., Scilingo, E. P., Landini, L., Guazzelli, M., Bicchi, A., Haxby, J.V., and Pietrini, P. (2007). The effect of visual experience on the development of functional architecture in hMT+. Cereb. Cortex 17, 2933-2939.

Rizzolatti, G. (2005). The mirror neuron system and its function in humans. Anat. Embryol. (Berl). 210, 419-421.

Rizzolatti, G., and Craighero, L. (2004). The mirror-neuron system. Annu. Rev. Neurosci. 27, 169-192.

Rizzolatti, G., and Fadiga, L. (1998). Grasping objects and grasping action meanings: the dual role of monkey rostroventral premotor cortex (area F5). Novartis Found. Symp. 218, 81-95; discussion 103.
Rizzolatti, G., Fadiga, L., Gallese, V., and Fogassi, L. (1996). Premotor cortex and the recognition of motor actions. Brain Res. Cogn. Brain Res. 3, 131-141.

Rizzolatti, G., and Sinigaglia, C. (2008). Further reflections on how we interpret the actions of others. Nature 455 , 589.

Rockland, K. S., and Ojima, H. (2003). Multisensory convergence in calcarine visual areas in macaque monkey. Int. J. Psychophysiol. 50,19-26.

Röder, B., Stick, O., Bien, S., Neville, H., and Rösler, F. (2002). Speech processing activates visual cortex in congenitally blind humans. Eur. J. Neurosci. $16,930-936$.

Röder, B., Teder-Sälejärvi, W., Sterr, A., Rösler, F., Hillyard, S. A., and Neville, H. (1999). Improved auditory spatial tuning in blind humans. Nature 400 , 162-166.

Sadato, N., Pascual-Leone, A., Grafman, J., Ibanez, V., Deiber, M. P., Dold, G., and Hallett,M. (1996).Activation of the primary visual cortex by Braille reading in blind subjects. Nature 380, 526-528.

Sani, L., Ricciardi, E., Gentili, C., Vanello, N., Haxby, J.V., and Pietrini, P. (2010). Effects of visual experience on the human MT+ functional connectivity networks: an fMRI study of motion perception in sighted and congenitally blind individuals. Front. Syst. Neurosci. 4:159. doi: 10.3389/fnsys.2010.00159

Sathian, K., and Zangaladze, A. (2002). Feeling with the mind's eye: contribution of visual cortex to tactile perception. Behav. Brain Res. 135, 127-132.

Schmid, M. C., Mrowka, S. W., Turchi, J., Saunders, R. C., Wilke, M., Peters, A. J., Ye, F. Q., and Leopold, D. A. (2010). Blindsight depends on the lateral geniculate nucleus. Nature 466, 373-377.

Scholz, J., Klein, M. C., Behrens, T. E., and Johansen-Berg, H. (2009). Training induces changes in whitematter architecture. Nat. Neurosci. 12, 1370-1371.

Shimony, J. S., Burton, H., Epstein, A. A., McLaren, D. G., Sun, S. W., and Snyder, A.Z. (2006). Diffusion tensor imaging reveals white matter reorganization in early blind humans. Cereb. Cortex 16, 1653-1661.

Stevens, A. A., Snodgrass, M., Schwartz, D., and Weaver, K. (2007). Preparatory activity in occipital cortex in early blind humans predicts auditory perceptual performance. J. Neurosci. 27, 10734-10741.

Théoret, H., Boire, D., Herbin, M., and Ptito, M. (2001). Anatomical sparing in the superior colliculus of hemispherectomized monkeys. Brain Res. $16,274-280$.

Toldi, J., Rojik, I., and Fehér, O. (1994). Neonatal monocular enucleationinduced cross-modal effects observed in the cortex of adult rat. Neuroscience $62,105-114$.

Tomaiuolo, F., Ptito, M., Marzi, C.A., Paus, T., and Ptito, A. (1997). Blindsight in hemispherectomized patients as revealed by spatial summation across the vertical meridian. Brain 120 795-803.

Tusa, R. J., and Ungerleider, L. G. (1985). The inferior longitudinal fasciculus: a reexamination in humans and monkeys. Ann. Neurol. 18, 583-591.

Ungerleider, L. G., and Mishkin, M. (1982). "Two cortical visual systems,' in Analysis of Visual Behavior, eds D. J. Ingle, M. A. Goodale, and R. J. W. Mansfield (Cambridge, MA: MIT Press), 549-586.

Vecchi, T., Cattaneo, Z., Monegato, M., Pece, A., Cornoldi, C., and Pietrini, P. (2006). Why Cyclops could not compete with Ulysses: monocular vision and mental images. Neuroreport 17, 723-726.

von Melchner, L., Pallas, S. L., and Sur, M. (2000). Visual behaviour mediated by retinal projections directed to the auditory pathway. Nature 404, 871-876.

Wallace, M. T., Ramachandran, R., and Stein, B. E. (2004). A revised view of sensory cortical parcellation. Proc. Natl. Acad. Sci. U.S.A. 101, 2167-2172.

Watson, J.D., Myers, R., Frackowiak, R. S., Hajnal, J. V., Woods, R. P., Mazziota, J. C., Shipp, S., and Zeki, S. (1993). Area V5 of the human brain: evi- dence from a combined study using positron emission tomography and magnetic resonance imaging. Cereb. Cortex 3, 79-94.

Weeks, R., Horwitz, B., Aziz-Sultan, A., Tian, B., Wessinger, C. M., Cohen, L. G., Hallett, M., and Rauschecker, J. P. (2000). A positron emission tomographic study of auditory localization in the congenitally blind. J. Neurosci. 20, 2664-2672.

Weiskrantz, L., Warrington, E. K., Sanders, M. D., and Marshall, J. (1974). Visual capacity in the hemianopic field following a restricted cortical ablation. Brain 97, 709-728.

Wittenberg, G. F. Werhahn, K. J., Wassermann, E. M., Herscovitch, P., and Cohen, L. G. (2004). Functional connectivity between somatosensory and visual cortex in early blind humans. Eur. J. Neurosci. 20, 1923-1927.

Zangaladze, A., Epstein, C. M., Grafton, S. T., and Sathian, K. (1999). Involvement of visual cortex in tactile discrimination of orientation. Nature 401, 587-590.

Conflict of Interest Statement: The authors declare that the research was conducted in the absence of any commercial or financial relationships that could be construed as a potential conflict of interest.

Received: 23 November 2010; paper pending published: 04 January 2011; accepted: 25 January 2011; published online: 14 February 2011.

Citation: Kupers R, Pietrini P, Ricciardi $E$ and Ptito $M$ (2011) The nature of consciousness in the visually deprived brain. Front. Psychology 2:19. doi: 10.3389/ fpsyg.2011.00019

This article was submitted to Frontiers in Consciousness Research, a specialty of Frontiers in Psychology.

Copyright $\odot 2011$ Kupers, Pietrini, Ricciardi and Ptito. This is an open-access article subject to an exclusive license agreement between the authors and Frontiers Media $S A$, which permits unrestricted use, distribution, and reproduction in any medium, provided the original authors and source are credited. 